\title{
СИНДРОМ ГИЙЕНА- БАРРЕ У БОЛЬНЫХ ПОСЛЕ ХИРУРГИЧЕСКОГО ВМЕШАТЕЛЬСТВА НА ЩИТОВИДНОЙ ЖЕЛЕЗЕ
}

\author{
'Ильин А.А., 'Исаев П.А., ${ }^{2}$ Румянцев П.О., 'Севрюков Ф.Е., 'Полькин В.В., 'Васильков С.В., 'Северская Н.В., \\ 'Панасейкин Ю.А.
}

'МРНЦ им А.Ф.Цыба - филиал ФГБУ «НМИРЦ» Минздрава России, Обнинск

${ }^{2}$ ФГБУ «НМИЦ эндокринологии» Минздрава России

ЦЕЛЬ: демонстрация развития редкого осложнения, возникающего после хирургического вмешательства на щитовидной железе

МАТЕРИАЛЫ И МЕТОДЫ: в течение 15 лет в клинике МРНЦ проведено хирургическое лечение 10320 больным по поводу опухолевой и узловой патологии щитовидной железы (ЩЖ). У 5 больных в раннем послеоперационном периоде развился синдром Гийена-Барре.

PЕзУльтАТЫ: у пяти больных в первые сутки после хирургического лечения отмечено возникновение затруднения дыхания. Во всех случаях выполнена тиреоидэктомия. Все пациенты женского пола, возраст больных была от 48 до 67 лет, медиана 54 года. Ни у кого из них не было повреждения возвратных нервов, ход их был прослежен во время операции. По данным гистологического исследования в 4 случаях диагностирован папиллярный рак щЖ, в одном - фолликулярная аденома. Во всех наблюдениях в окружающей тиреоидной ткани выявлено наличие аутоиммунного процесса. У четырех больных диагностирован хронический тиреоидит, в одном - диффузный токсический зоб. Кроме того, у одной больной заболевание протекало на фоне бронхиальной астмы. У всех больных после выхода из наркоза отсутствовали нарушения дыхания, и была сохранена фонация. В течение последующих 6 ч у них появилась инспираторная одышка. Помимо затруднения дыханий у больных имелась дополнительная неврологическая симптоматика: бульбарные расстройства у 5, мышечная слабость у 2, потеря чувствительности по типу «перчаток» и «носков» у 3, симметричный вялый парез в ногах, сопровождающийся нарушением походки у 1. Больным проводилась специфическая терапия. Во всех случаях внутримышечное введение иммуноглобулина G (у 3 - октагам из расчета 0,4 г/кг/сут, у 2 иммуноглобулин человеческий нормальный 1,5 мл/сут) в течение 5 дней. Трем больным проведено по два сеанса плазмафереза. Улучшение состояния больных отмечалось в первые сутки после начала специфической терапии. Полное исчезновение симптомов заболевания произошло в течение 6 месяцев поле операции. Больные осмотрены ЛОР-врачом подвижность голосовых связок сохранена.

По данным литературы, синдром Гийена-Барре встречается у 2-3 человек на 100000 человек, при этом выделяются два пика в возрастных группах 20-25 и старше 60 лет. В нашей группе развитие синдрома отмечено достоверно чаще (р менее 0,001) и пик числа наблюдений пришелся на 52 года. Возможно заболевание развивается чаще, но не всегда диагностируется из-за при отсутствии ярко выраженной симптоматики.

ВЫВОДЫ: при проведении хирургического вмешательства на щЖ, при наличии сопутствующей аутоиммунной патологии, в раннем послеоперационном периоде, возможно развитие синдрома Гийена-Барре. Заболевание следует дифференцировать с травматизацией гортанных нервов и иной неврологической патологией. Стандартная лечебная схема ведения синдрома Гийена-Барре (введение иммуноглобулина G и проведение плазмафереза) демонстрируют в этом случае высокую эффективность.

КЛЮЧЕВЫЕ СЛОВА: сИндром Гийена-Барре; хирургическое лечение; щитовидная железа. 